\section{Gutted programs and}

\section{children's guts}

I n polite parlance, it could be said educational administrators have now seen the error of their ways. After gutting physical education programs in the nation's schools a decade ago, they're now madly scrambling to revitalize previously robust physical education programs in the face of a near epidemic of childhood obesity.

Yet, as educators move full circle, they also find themselves embroiled in a debate over whether noninstructional physical activity time, or what's euphemistically referred to as "daily physical activity," as opposed to physical education programming, is an adequate means of improving fitness.

Child health advocates say that getting getting kids more active is unquestionably beneficial. But they're also worried that the trend towards "daily physical activity" is actually a means of doing-it-on-the-cheap and might ultimately damage the quality of physical education in Canada.

It's an issue driven largely by the concerns about childhood obesity, says Grant McManes, president of the Canadian Association for Health, Physical Education, Recreation and Dance. It's put pressure on educators to reinvigorate physical education programs, he says. "I think there has been a change in attitudes towards physical education over the last decade. There has been widespread curriculum review in the area of physical education and in some cases health education across the country."

Concern about childhood obesity becoming epidemic emerged in the rggos after a "back to basics" philosophy that guided curriculum development resulted in significant cutbacks to arts and physical education programs. Subsequent research has consistently shown that the weight of children has since spiralled.

Prior to 2004, the last time the height and weight of a nationally representative sample of youth aged 2-I7 were directly measured was in the Canada Health Sur-

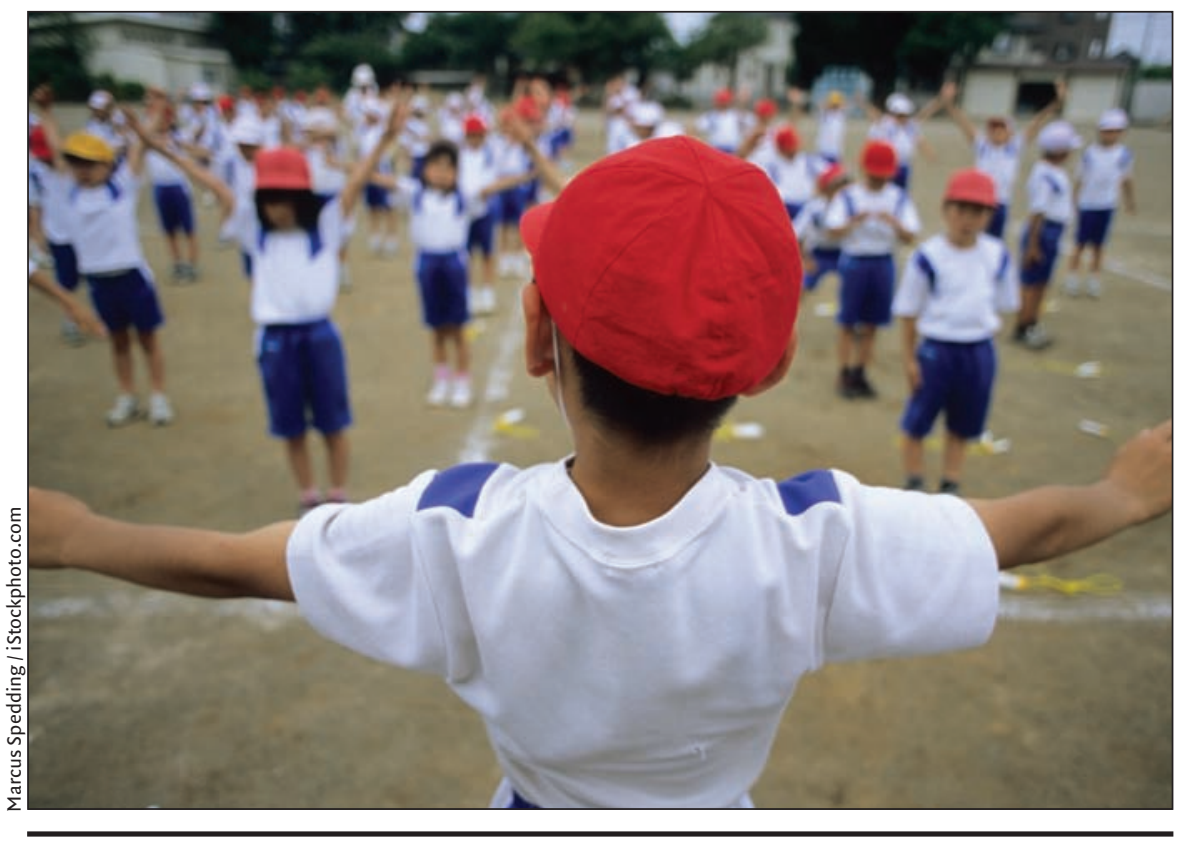

The so-called epidemic of childhood obesity appeared to ensue after provincial educational administrators began slashing physical education programming as a cost-cutting measure. Now that children's waistlines are expanding, there's extensive debate about whether to restore physical education programs or to introduce less onerous forms of exercise involving "physical activity" such as a stroll at recess.

vey of $1978 / 79$. Since then, the prevalence of overweight and obesity in children and adolescents has almost doubled, from $15 \%$ to $26 \%$ in 2004 .

In response, more and more provinces are moving to increase the amount of physical education and physical activity that kids get while they are at school. It's also argued that the focus of programs has shifted. While 20 or even Io years ago the goal of physical education was to train athletes, provinces are now broadening the scope of health and physical education to emphasize personal goals and healthy living.

It's an individual wellness approach favored by Mark Sokolowski, a physical education specialist at La Verendrye, an early- and middle-years school in Portage la Prairie, Manitoba. It generates results, he says. "When we changed the wording and the focus of the phys. ed. and made it more of a personal improvement as opposed to meeting standards, kids who don't like phys. ed. or who are intimidated are doing better. They are finding that they don't have to be the best in the class to do well in phys. ed. My results don't lie. The kids' results are getting better and their cardio is improving."

School boards across the country are now embracing the strategy. But each province's approach varies.

"That's the biggest thing - the differences across the country," says Amanda Stewart Stenac, an assistant professor in the Faculty of Education at St. Francis Xavier University.

Stenac is completing an environmental scan comparing physical education and activity policies across the country on behalf of the Joint Consortium for School Health and the Canadian Association for Health, Physical Education, Recreation and Dance. The results should give educators and policy makers a better sense of the respective merits of various approaches.

For now, the provinces appear divided in 2 camps.

In one camp, some provinces are beefing up physical education requirements to ensure that kids have the 


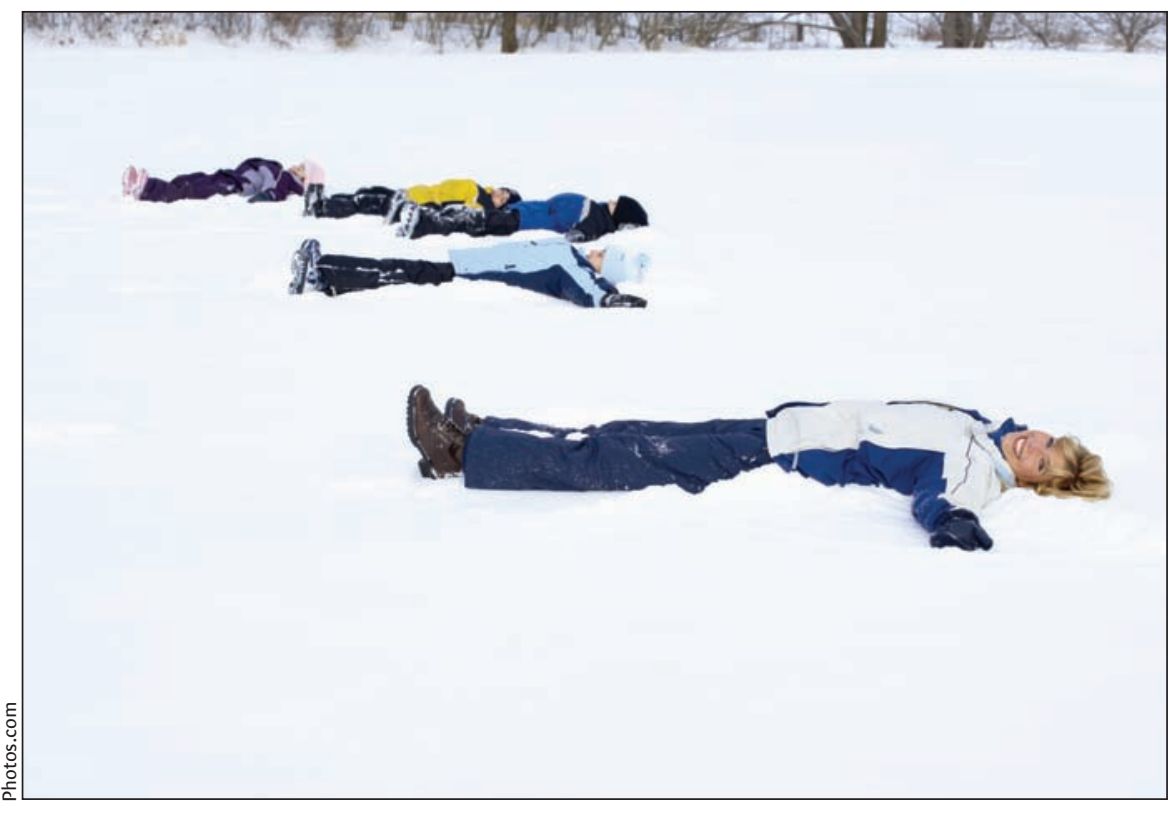

Proponents of physical activity, as opposed to physical education classes, contend that a brief fitness break during class, a walk or occasional participation in intramural sports are an adequate approach to promoting fitness among children. Researchers are now conducting an environmental scan comparing the respective merits of physical education and physical activity.

knowledge and skills to be physically active. Newfoundland and Labrador has steadily increased the required amount of physical education for kids starting with the kindergarten curriculum in 200I. A grade II requirement came into effect in 2005, and a grade 12 last fall.

Starting in the next school year, Nova Scotia will require a grade Io phys. ed. credit, while Manitoba will become just the second province to mandate a specific amount of time that kids must actually spend in physical education classes. Quebec was the first, moving in 2006 to require, rather than recommend, that students participate in 90 minutes of physical education instructional time each week.

Other provinces are going an alternate route and are mandating that schools provide kids with a specified amount of daily physical activity, often in such forms as "a fitness break" during classroom time, activities at recess or intramural sports. In 2003, Alberta became the first province to announce plans to require 30 minutes of physical activity for students in grades $\mathrm{I}$ to 9 . Ontario followed suit in September 2005 with a plan for 20 minutes per day for grade I to 8 students. Next fall, all stu- dents in grades I to 9 in British Columbia will be getting 30 minutes per day, while students in grades Io to I 2 will have to log at least 150 minutes of moderate to vigorous activity each week.

"The trend in some ways is leaning towards DPA [daily physical activity]," says Stenac. "That's where the lack of evaluation could be a problem. We don't truly know what the implications of DPA are."

Stenic's concerns are echoed by a number of physical education and activity advocates. Mark Tremblay, a noted childhood obesity and activity researcher and chair of Active Healthy Kids Canada, says most people don't understand the difference between physical education and physical activity. "For many, they're equated, and that's because we don't have enough physical educators in the system to educate parents and other teachers about the importance of it."

"Certainly there appears to be a trend across the country to implement physical activity, which is great because continuous physical activity is absolutely necessary and we need more of it," says Tremblay. "But not at the expense of teaching our kids how to be physically literate. These should not be trade-offs."

While it's a positive sign that provincial governments are taking steps to make kids more active, the initiatives must be monitored to ensure that fitness goals are met, Tremblay says. "The biggest complaint I'd have with DPA [daily physical activity] is that no one knows what's happening with it because it's not being assessed. Is it displacing phys ed? Is it having the desired effect? Is it having the opposite effect?"

Tremblay adds that the 2 provinces that have mandated daily physical activity, Ontario and Alberta, have not committed to any significant assessment of the program and have not evaluated fitness levels before and after implementation.

Anecdotally, Tremblay says his 4 school-age children often say they don't get daily physical activity in their Ontario schools. "In my kids' schools, sometimes DPA displaces physical education. More often it just doesn't occur. If you survey superintendents, they'll say 'of course it's happening in every school in their district.' If you ask principals, they'll say 'of course it's happening in all of their classes.' If you get down to the student, and you ask them if it's happening, it's a funny thing - somewhere along the line, it didn't happen."

Evaluation of the efficacy of daily physical activity approaches is essential, Tremblay adds. "If you want to make a change, you've got to inspect it, not just expect it."

Without proof that such programming makes kids more active, policymakers might ultimately conclude that the approach is ineffective, Tremblay says. "My concern is that ro years from now, with DPA in place, we're still going to see childhood obesity rates continuing to go up, metabolic dysfunction increasingly evident in kids, yet we've had this 'massively successful invention' through the school system where every kid is getting $x$-number of minutes of physical activity per day. So we're going to conclude that the relationship isn't there - that maybe physical activity isn't as important as we thought."

Others are concerned that daily physical activity initiatives might lead 
to the demise of physical education curriculum. "A big fear among curriculum support folks is that a minister might say to another minister that DPA is really great, and that minister might come back and the next thing you know there's no physical education in schools," says Stenac.

Manitoba opted for the physical education approach because there's an implicit "higher level of rigour in the teaching of physical education" than in daily physical activity, says JeanVianney Auclair, assistant deputy minister of Education, Citizenship and Youth for Manitoba. "For us, it's a better quality education."

Tremblay laments that responsibility for delivering physical education curriculum is often vested with school boards, which results in significant inconsistencies within provinces and the country.

McManes, meanwhile, hopes that more provinces will ultimately opt for the physical education route, and then put resources in place to ensure that physical education is taught by qualified personnel.

Defenders of the daily physical activity approach argue that current models of physical education aren't engaging students. Guy Faulkner, an assistant professor of physical education and health at the University of Toronto, found a significant linear decrease in the number of students choosing to enroll in optional physical education credits in Ontario high schools. Part of the reason is that physical education has to compete with other subjects that are viewed as higher priorities.

Yet the kids that don't want to take physical education are the ones who could benefit from it the most, Faulkner says. "I think if kids are choosing physical education, it's much more likely to lead to a lifelong interest in physical activity, rather than feeling that you're forced into doing it. I think that when you force people to take phys ed, you get people who don't enjoy it or appreciate it whatsoever."

Schools should be thinking of more creative options to make physical education an attractive option, he adds. Laura Mueller, Ottawa, Ont.

DOI:I0.1503/cmaj.08003I

\section{News@a glance}

Fit patients: A survey of the opinions of 870 British family and hospital doctors published in The Telegraph's Doctor magazine on Jan. 28, 2008, indicated many believe patients should be denied medical treatment because of lifestyle. Some $94 \%$ believe alcoholics who won't stop drinking should be denied liver transplants; while 50\% believe smokers should be denied heart bypass surgery. About one-third believe the elderly should be denied surgery.

More students: The Manitoba government will invest \$3 million to create ro new spots for medical students at the University of Manitoba Faculty of Medicine, thereby raising the number of available spaces to IIo from roo. Wayne Kondro, CMAJ

DOI:I0.I503/cmaj.0802I3

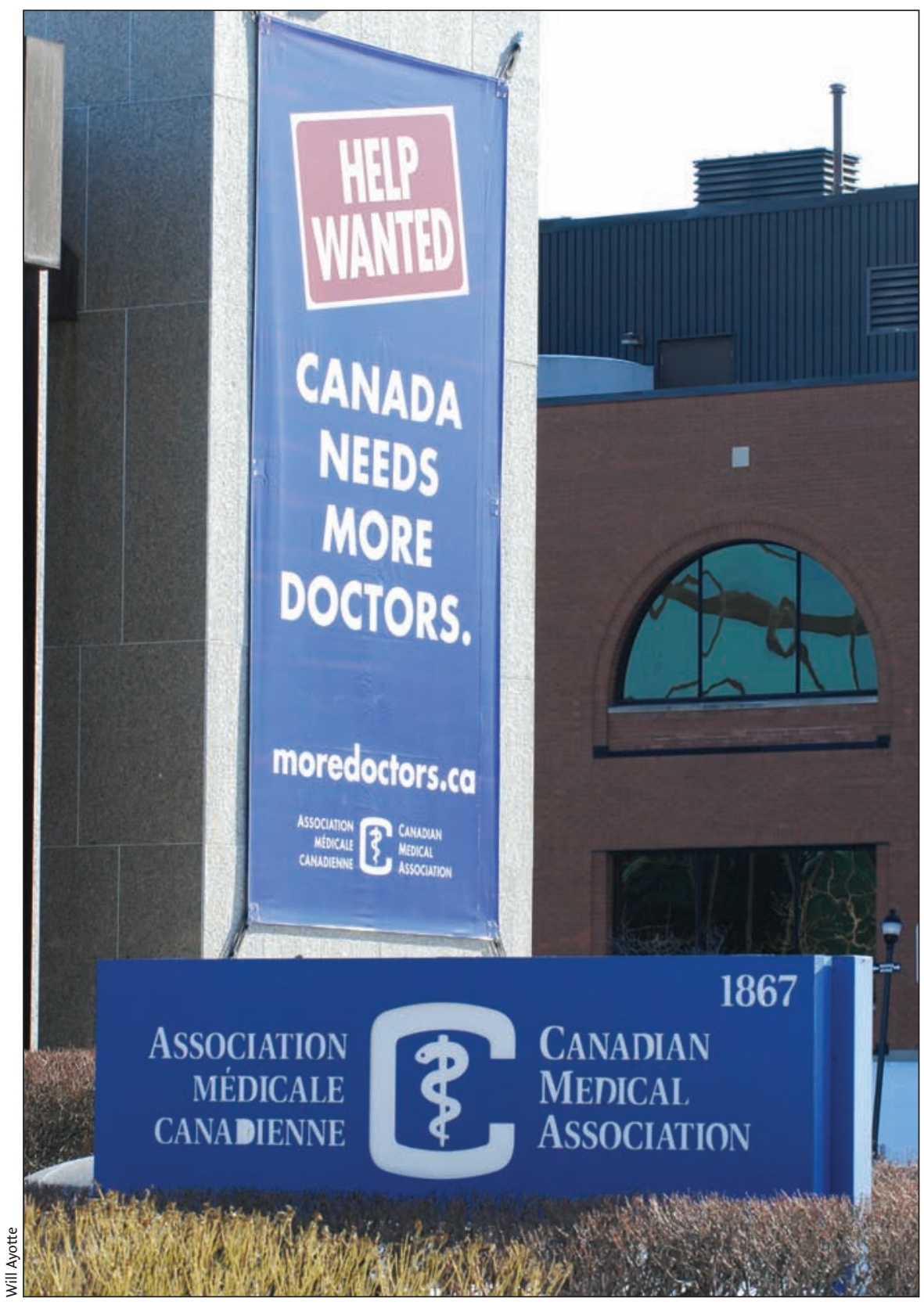

Perhaps the world's largest want ads have been strung from the exterior walls of CMA House as part of the national association's new "More Doctors, More Care" campaign, which aims to elevate the physician-shortage issue onto the nation's political agenda. 